\title{
The Prevalence of Eye and Vision Problems among Rural Egyptians Preschooler
}

\author{
Manal Hassan Abuelela ${ }^{1 *}$, Adel Aleieldin ${ }^{2}$ and Ahmed Hamdi Aboelyamin ${ }^{1}$ \\ ${ }^{1}$ Department of Public Health, Research Institute of Ophthalmology, Egypt \\ ${ }^{2}$ Department of Pediatric Ophthalmology, Research Institute of Ophthalmology, Egypt
}

*Corresponding author: Manal Hassan Abuelela, Department of public health, Research Institute of Ophthalmology, Egypt.

Received Date: Octobert 04, 2018

Published Date: October 30, 2018

\begin{abstract}
Objectives: The aim of this study was to determine the prevalence of visual impairment and percent distribution of childhood diseases affecting vision among preschool children (one day to 6 years) in Giza governorates of Egypt as a first step in National survey.

Methods: A population-based survey was conducted on a multistage cluster sampling. Target population was one day to 6 years children living in rural areas of Giza, governorate using systematic random samples based on birth records. The total sample of children includes 4470 preschool children; 2304 males and 2166 females. They are socio-demographically surveyed for their living condition.

Results: The total number of children subjected for ophthalmologic examination, visual assessment, genetic and pediatric examination were 2603 child. About $40 \%$ of them were diagnosed to have different eye problems. About $7.4 \%$ of examined children were diagnosed to have different genetic problems.

Conclusion: This survey could be considered as the first building block of Egyptian health map by providing a baseline data on childhood blindness helping Egyptian health community direct their health services towards the actual needs present in the community.
\end{abstract}

Keywords: Prevalence; Preschooler; Eye problems; Rural; Egypt

\section{Introduction}

Health of our children is a top priority that is why preventive care services- such as physical exams, immunizations, and routine screenings-can help our children avoid serious health problems and allow early detection and proper management of common medical conditions [1]. Childhood blindness is a major concern of the national health programs due to its economic burden on nations. In the same time, effective preventive measure can save considerable disability adjusted life years (DALY) [2]. Early detection of blinding eye diseases at the primary health level and organized referrals and prompt management by qualified ophthalmologists at secondary and tertiary levels in last decade were the strategies of the eye health care programs to reduce the childhood blindness [3]. In the same time, according to WHO data there is no national plan for prevention of blindness in Egypt [4] this brought about the idea of this survey to set the first building block of Egyptian health map by providing a baseline data on childhood blindness helping Egyptian health community direct their health services towards the actual needs present in the community.

\section{Materials and Methods}

\section{Study design and sampling technique}

Target population was one day to 6 years children living in households in Giza, governorate. Throughout the period of eighteen months. A community based cross-sectional study was conducted on a multistage cluster sampling. A preliminary pilot study was carried out in kafer-Hakeem village (300 child) to determine a rough estimate of the expected prevalence and test validity of tools and feasibility of the action plan used in the survey.

The sample size was calculated using Epi-info version 9 by assuming the estimated prevalence of vision disorders among pre- 
school children was $0.1 \%$. The confidence level was $95 \%$. According to the population census of 2006 . The calculated sample size was 1840. Eight villages were selected by simple random technique, and then children were selected systematically from birth records in the health units after exclusion of deaths and those who are not actual residents of the selected villages to obtain names and addresses.

\section{Data collection}

Data were collected through personal interview with mothers of the selected children after taking their consent for participation during household visits. They were asked to fulfill a specially designed questionnaire that included different items about : 1 . socio-demographic; Child :name, age, birth date, gender, previous eye complaint, Parents: ages, level of education and their occupation, number of offspring, number of inhabitants/household, Brothers' and sisters' ages, gender, presence of eye complaint of all who were 6 years old or less at time of survey. 2. Home environment data; type of building material, numbers of rooms per house, window space, home ventilation, exposure of rooms and bed dressing to sunlight, water supply, sewage disposal and presence of animals and/or birds. 3. Health services; availability, accessibility, type, presence of an ophthalmologist in that villages, their attitudes and traditions in the presence of eye complaints.

\section{Full pediatric and ophthalmologic examinations}

All children were subjected to full clinical examination and provision of care that was carried out in the health units at the selected villages by specialized doctors in the field of visual assessment, ophthalmology, genetics, pediatrics. About 75 preschool children were examined/ visit. Screening of each village took 6 clinical visits. Referral of cases who needed further investigations and /or interference in research institute of ophthalmology. Various screening tests that were used to identify visual impairment among children. These tests include visual acuity tests, stereo-acuity tests, the cover-uncover test, and the Hirschberg light reflex test (for ocular alignment/strabismus), as well as the use of auto-refractors (automated optical instruments that detect refractive errors).

\section{Statistical Analysis}

A computerized database for survey data was developed. Eighty-two fields of information were recorded for each child. Data entry and statistical analysis was carried out using SPSS (Statistical Package for Social Science) version 18. Spot-checks and re-checks on sample data were conducted by supervisors for quality control. Both descriptive and analytical statistics were performed. The data analysis began with calculation of frequencies and percentages of the variables of interest. Linear regressions were then carried out to determine the most important predictors of ophthalmic diseases. Statistical significance was assessed at $5 \%$ level.

\section{Result}

The total sample of children included 4470 preschool children; 2304 males and 2166 females (Table 1). They were socio-demographically surveyed for their living conditions (Table 2). The characteristics of the studied sample are given in Table 1. Two thousand, six hundred and three children were subjected for ophthalmologic examination, visual assessment, genetic and pediatric examination, who constituted $58.2 \%$ of the total sample included in our study (Figure 1). About $40 \%$ of them were diagnosed to have different eye problems (Table 3). The number of children referred to the ophthalmologists at RIO specialized ophthalmic clinics for further assessment was 156 (15\%) of diagnosed cases (Figure 2) (Figure 3). Seventy-five (7.2\%) of diagnosed children to have different eye problems kept their appointment. About $7.4 \%$ of those children subjected for clinical examination were diagnosed to have different genetic problems. About $22 \%$ of them were diagnosed to have different pediatric health problems. On Linear Regression analysis it has been found that: low level of mother education, low home cleanness and unavailability of ophthalmic specialist are predictors of eye infections of the examined children (P-values are 0.001, 0.002 and 0.003 respectively). While older aged children $(\mathrm{P}<0.001)$ and unavailability of ophthalmic specialist $(\mathrm{P}=0.002)$ are predictors of refractive errors. There is a direct significant relationship between occurrence of strabismus, errors of refraction and incubation with $\mathrm{O}_{2}$ supply (P-value $=0.024$ and 0.032 respectively).

Table 1: Characteristics of the selected sample $(n=4470)$.

\begin{tabular}{|c|c|c|}
\hline & No & $\%$ \\
\hline \multicolumn{3}{|c|}{ Gender } \\
\hline Males & 2304 & 51.5 \\
\hline Females & 2166 & 48.5 \\
\hline \multicolumn{3}{|l|}{ Age Groups } \\
\hline$<3$ months & 225 & 5 \\
\hline 3-6 months & 149 & 3.3 \\
\hline 6-12 months & 305 & 6.8 \\
\hline 1- 2 years & 881 & 19.7 \\
\hline 2-3 years & 685 & 15.3 \\
\hline 3-4 years & 735 & 16.4 \\
\hline 4-5 years & 660 & 14.8 \\
\hline 5-6 years & 830 & 18.6 \\
\hline \multicolumn{3}{|c|}{ Employment Status of Fathers } \\
\hline Yes & 4272 & 95.6 \\
\hline No & 198 & 4.4 \\
\hline \multicolumn{3}{|c|}{ Employment Status of Mothers } \\
\hline Yes & 272 & 6.1 \\
\hline No & 4198 & 93.9 \\
\hline \multicolumn{3}{|c|}{ Level of Education among Fathers } \\
\hline Illiterate & 1408 & 31.5 \\
\hline Basic education & 1044 & 23.4 \\
\hline Secondary & 1558 & 34.9 \\
\hline High (University) & 460 & 10.3 \\
\hline \multicolumn{3}{|c|}{ Level of Education among Mothers } \\
\hline Illiterate & 1408 & 31.5 \\
\hline Basic education & 1044 & 23.4 \\
\hline Secondary & 1558 & 34.9 \\
\hline High (University) & 460 & 10.3 \\
\hline $\begin{array}{c}\text { Accessibility of Health } \\
\text { Services }\end{array}$ & 3838 & 85.9 \\
\hline \multicolumn{3}{|l|}{ Yes } \\
\hline No & 632 & 14.1 \\
\hline
\end{tabular}




\begin{tabular}{|c|c|c|}
\hline \multicolumn{3}{|c|}{ Availability of an Ophthalmologist } \\
\hline Yes & 510 & 11.4 \\
\hline No & 3960 & 88.6 \\
\hline
\end{tabular}

Table 2: Distribution of the selected sample according to their living conditions.

\begin{tabular}{|c|c|c|}
\hline & No & $\%$ \\
\hline \multicolumn{3}{|c|}{ Source of water supply } \\
\hline Stored water channel & 23 & 0.5 \\
\hline $\begin{array}{l}\text { Running water } \\
\text { channel }\end{array}$ & 27 & 0.6 \\
\hline Stored Tape/pump & 1648 & 36.9 \\
\hline Running Tape/pump & 2730 & 61.1 \\
\hline Others & 42 & 0.9 \\
\hline \multicolumn{3}{|c|}{ Type of Building Material of Households } \\
\hline Mud & 63 & 1.4 \\
\hline Raw Brick & 175 & 3.9 \\
\hline Red Brick & 3934 & 88 \\
\hline Stones & 125 & 2.8 \\
\hline Wood & 5 & 0.1 \\
\hline Tents & 6 & 0.1 \\
\hline Others & 162 & 3.6 \\
\hline \multicolumn{3}{|c|}{ Good Ventilation } \\
\hline Yes & 4114 & 92 \\
\hline No & 356 & 8 \\
\hline \multicolumn{3}{|c|}{ Good Lighting Conditions } \\
\hline Yes & 4031 & 90.2 \\
\hline No & 439 & 9.8 \\
\hline \multicolumn{3}{|c|}{ Sanitary Latrine } \\
\hline Yes & 3711 & 83 \\
\hline No & 759 & 17 \\
\hline \multicolumn{3}{|c|}{ Availability of Electricity } \\
\hline Yes & 4217 & 94.3 \\
\hline No & 253 & 5.7 \\
\hline \multicolumn{3}{|c|}{ Availability of Radio \& TV } \\
\hline Yes & 4078 & 91.2 \\
\hline No & 392 & 8.8 \\
\hline
\end{tabular}

Table 3: Distribution of eye diseases among examined children.

\begin{tabular}{|c|c|c|}
\hline & No & $\%$ \\
\hline Errors of refraction & 822 & 31.6 \\
\hline Conjunctiva infections & 386 & 14.8 \\
\hline Strabismus & 155 & 6 \\
\hline Eyelids (ptosis, chalazion, blepharitis, & 72 & 2.8 \\
\hline NLDO) & 11 & 0.4 \\
\hline Amblyopia & 10 & 0.4 \\
\hline Abnormal color vision & 9 & 0.3 \\
\hline Corneal opacity, ulcer, megalocornea & 8 & 0.31 \\
\hline Optic nerve atrophy & 3 & 0.1 \\
\hline Pinpoint & 2 & 0.1 \\
\hline Congenital cataract & 1 & 0.04 \\
\hline Congenital glaucoma & & \\
\hline
\end{tabular}

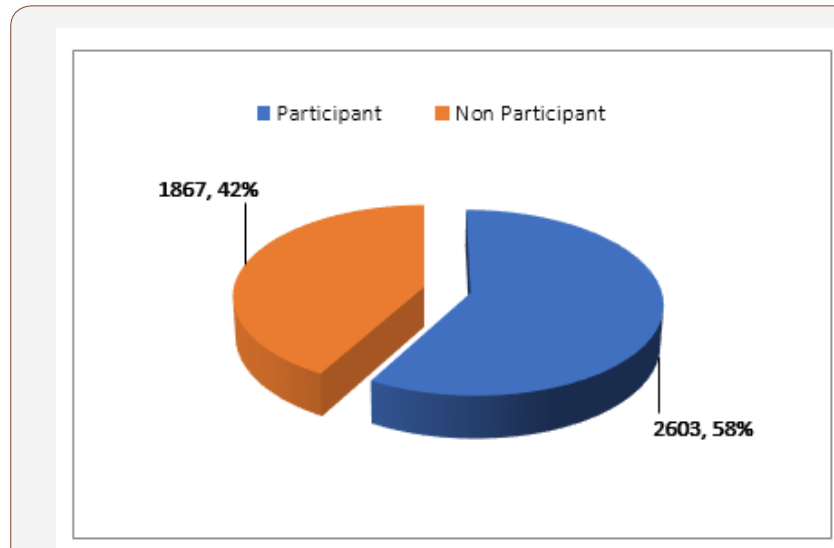

Figure 1: Response Status of the Selected Sample of Children.

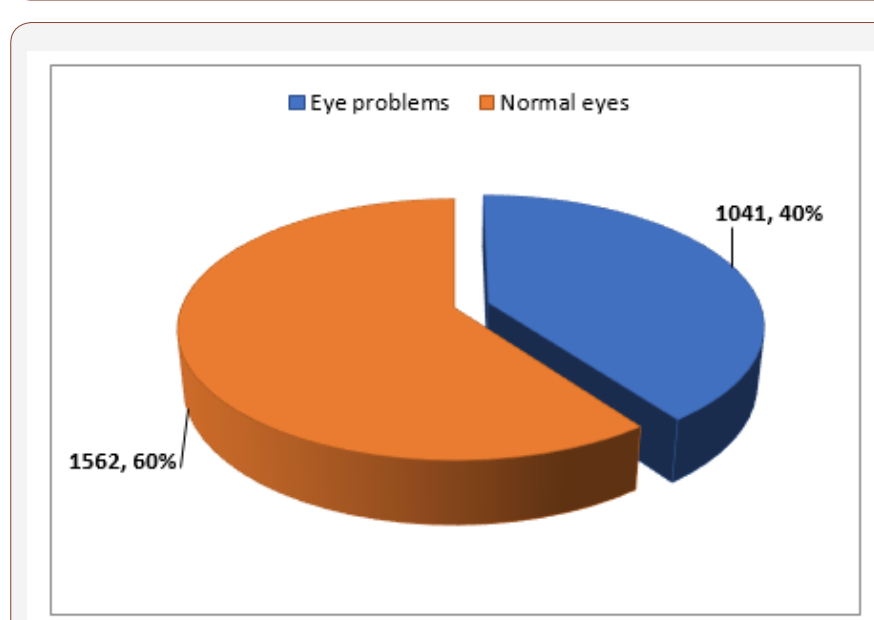

Figure 2: Prevalence of Eye Problems Among Studied Children.

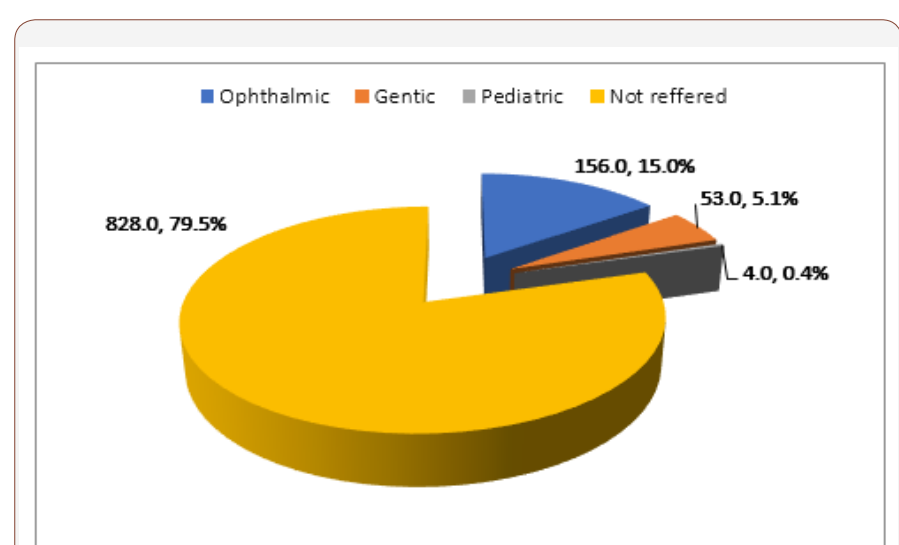

Figure 3: Frequency Distribution of referred Children Who Had Different Eye Problems to RIO Clinics for Management.

\section{Discussion}

The importance of screening for visual problems in childhood is based on the recognition that $5 \%$ to $10 \%$ of preschoolers will have difficulties which, if left untreated, may interfere with the proper development of visual acuity[5].The goal of vision screening is to detect subnormal vision or risk factors that threaten visual development, preferably at a time when treatment can be initiated to yield the highest benefit and to improve their quality of life. A primary goal of vision screening in young children is the detection 
of amblyopia or the risk factors for development of amblyopia, a neural deficit in vision that is estimated to be present in $1 \%$ to $4 \%$ of children $[6,7]$.

Health services are available to $88.6 \%$ of sampled children and only $11 \%$ had accessibility to an ophthalmic specialist in the studied villages. It has been observed that many children were detected with eye problems and defective visions for the first time in our study. This supported the recommendation that adoption of universal vision and eye screening for preschool children is a must. We could identify 1041(40\%) children with eye problems during screening which was much higher than that $(4.5 \%)$ of Oman preschool children reported by Khandekal et al. [8] Oman has wellestablished primary health care (PHC) services which are easily accessible. Our prevalence estimate was also higher than $(7.0 \%)$ of Saudi Arabian preschool children reported by Al-Rowaily [9].

The prevalence of eye diseases in our study differ from those in other countries. This return to ethnic groups, the difference in environment and atmosphere, and the difference in culture of people. Our prevalence estimate $(6.0 \%)$ for strabismus in Preschool rural Egyptian children was much higher than in young Singaporean Chinese children aged 6 to 72 months, (0.80\%) [10], Hispanic/Latino (2.4\%) and African-American (2.5\%) children who participated in the MEPEDS and also compared with Caucasian $(3.3 \%)$ and African-American (2.1\%) children in the BPEDS [11,12] It was also higher than in children aged between 4 and 7 years in the United States, United Kingdom, and Australia where the reported prevalence has ranged from $2.3 \%$ to $3.4 \%$ (Table 1) [1315]. Similar lower strabismus prevalence have been reported in other East Asian communities, such as those in Australia, Japan, and China [16]. and was also higher than $(2.7 \%)$ in under five years old children in Oman [8] and was much higher that that $(0.5 \%)$ reported among 4 to 6 years old Saudi Arabian children [9]. The prevalence estimate of amblyopia was $0.4 \%$ among studied children which is much lower than that reported by Friedman et al. [12]; Mc Kean-Cowdin et al. [17]; MEPEDS, 2008 (0.8\% to 2.6\%) among children in United states. On the other hand, they reported lower prevalence of strabismus $(2.1 \%$ to $3.5 \%)$, than that of our study (6\%). Also strabismus constituted higher prevalence than that $(2.7 \%)$ reported among preschool children in Oman [8] and (1.2\%) among preschool Singaporean Chinese children aged 6 to 72 months [10]. It was more similar to that found in Saudi Arabian $(0.5 \%)$ children in Riyadh [9]. Differences in study design and the lack of a consistent definition of amblyopia makes comparison with other studies difficult [17].

Refractive error, and myopia in particular, is one of the five leading causes of visual impairment in the world [18]. It is estimated that, by 2020, approximately one third of the world's population (2.5 billion) will be affected by myopia alone [19]. The prevalence of refractive error in children, particularly before the typical school commencement age of 6 to 7 years, has been assessed in only a limited number of population-based studies. Pediatric studies exploring refractive error have provided useful insights into the early development of refractive error [20]. The reduced vision that results from refractive error may affect academic performance, that can reduce choice of occupation and, therefore, socio-economic status in adult life. This can have a detrimental effect on both the individual and their community. Reduced vision can also impair the ability and inclination of a child to participate in class and to join in with peer sports and social activities thereby impeding personal development $[21,22]$.

In our study, out of the 2603 children, 822 children were diagnosed as having one or more refractive error, with an over-all prevalence of $31.6 \%$. Upon the comparison of our estimates with those of other studies, we found them to be higher than those of a study conducted in Egypt (22.1\%) [23] and higher than those of studies conducted in countries like Saudi Arabian (4.5\% to 23\%) $(9,24,25)$, Qatar (19.7\%) [24-26], Nepal (8.6\%) [27] and India (13.09\%) [28]. Our prevalence was also higher than Taiwan's and Srinagar's [29,30], Singaporean Chinese preschool children (21.6\%) [31], African Americans (27.2\%), White Americans (22.5\%) [32]. Our prevalence was lower than Sweden study (35.0\%) [33] and much lower than Southern China study (56.6\%) [16]. The variation in prevalence could be attributed to the differences in definition of refractive error, age compositions of the study population, and refractive error measurement techniques.

Cataract is among the leading causes of blindness world-wide. [34] Additionally, although congenital cataract constitutes only a small proportion of these cases, it is one of the primary causes of treatable childhood blindness [35]. The prevalence of congenital cataract has been reported from 1 to 15 per 10,000 children worldwide, whereas it ranges from 1 to 3 per 10,000 births in developing countries. [35] The number of blind children due to congenital cataracts globally and in developing countries are 200,000 and 133,000, respectively [34]. The prevalence estimate of congenital cataract in our study was $0.08 \%$ i.e. $8 / 10000$ preschool children. To our knowledge, published reports on population-based assessments of the prevalence and incidence of congenital cataract have been unavailable until now. Some available small-population studies have shown that the incidence of congenital cataract is approximately 5.0 per 10,000 births in China. In a large population, hospitals-based study, it has been found that congenital cataract patients accounted for $2.39 \%$ of Chinese children [35].

\section{Conclusion}

Preschool vision screening is critical to improving long-term vision outcomes. Unfortunately, many children do not receive timely vision screening. Public health activities, including work by Research Institute of Ophthalmology community outreach programs to improve surveillance and the delivery of vision screening within primary care settings, and state and local efforts to provide screening within the community, are central to decreasing the long-term morbidity associated with blinding eye diseases.

\section{Conflict of Interest}

The authors declare no conflict of interest, financial or otherwise.

\section{Acknowledgment}

We would like to thank the Ministry of health and population for supporting this study. We are also highly indebted to the study 
participants, who sacrificed their time and participated actively in the study. We thank Mr. Magdy Aziz for his great support.

\section{References}

1. Frieden TR, Centers for Disease Control and Prevention (2014) Use of selected clinical preventive services to improve the health of infants, children, and adolescents-United States, 1999-2011. MMWR supplement 63(2): 1-2.

2. World Health Organization (2006) Vision 2020 action plan for 2006-2011planning meeting. Geneva, 11-13 July.

3. Clare Gilbert, Allen Foster (2001) Childhood blindness in the context of Vision 2020-the right to sight. Bulletin of the World Health Organization 79(3): 227-232.

4. Resnikoff S, Pascolini D, Etya'ale D, Kocur I, Pararajasegaram R, et al. (2004) Global data on visual impairment in the year 2002. Bulletin of the World Health Organization 82(11): 844-851.

5. Canadian pediatric Society (2009) Vision screening in infants, children and youth. Paediatr Child Health 14(4): 246-248.

6. Miller JM, Lessin HR (2012) American Academy of Pediatrics Section on Ophthalmology and Committee on Practice and Ambulatory Medicine, American Academy of Ophthalmology, American Association for Pediatric Ophthalmology and Strabismus, and American Association of Certified Orthoptists Instrument-based pediatric vision screening policy statement. Pediatrics 130(5): 983-986.

7. US Preventive Services Task Force (2011) Vision screening for children 1 to 5 years of age: US Preventive Services Task Force recommendation statement. Pediatrics 127(2): 340-346.

8. Khandekar R, Al Harby S, Mohammed A (2010) Eye and vision defects in under-five-year-old children in Oman: A public health intervention study. Oman J Ophthalmol 3(1): 13-17.

9. Mohammad A. Al-Rowaily (2010) Prevalence of refractive errors among pre-school children at King Abdulaziz Medical City, Riyadh, Saudi Arabia . Saudi J Ophthalmol, 24 (2): 45-48.

10. Chia A, Dirani M, Chan Yh, Gazzard G, Au Eong Kg, et al. (2010) Prevalence of amblyopia and strabismus in young singaporean chinese children Invest Ophthalmol Vis Sci 51(7): 3411-3417.

11. MEPEDS (Multi-Ethnic Pediatric Eye Disease Study) Group (2008) Prevalence of amblyopia and strabismus in African American and Hispanic children ages 6 to 72 months: The multi-ethnic pediatric eye disease study. Ophthalmology 115(7): 1229-1236.

12. Friedman DS, Repka MX, Katz J, Giordano L, Ibironke J, et al. (2009) Prevalence of amblyopia and strabismus in White and African American children aged 6 through 71 months: The Baltimore pediatric eye disease study. Ophthalmology. 116(11): 2128-2134.

13. Newman DK, Hitchcock A, McCarthy H, Keast-Butler J, Moore AT (1996) Preschool vision screening: outcome of children referred to the hospital eye service. Br J Ophthalmol 80(12): 1077-1082.

14. Robaei D, Rose KA, Ojaimi E, Kifley A. Martin FJ, et al. (2006) Causes and associations of amblyopia in a population based sample of 6-years old Australian children. Arch Ophthalmol 124(6): 878-884.

15. Robaei D, Kifley A, Mitchell P (2006) Factors Associated with a Previous Diagnosis of Strabismus in a Population Based Sample of 12-Year Old Australian Children. Am J Ophthalmol 142(6): 1085-1088.

16. He M, Zeng J, LiuY, Xu J, Pokbarel GP, et al. (2004) Refractive error and visual impairment in urban children in Southern China. Invest Ophthalmol Vis Sci 45: 793-799.

17. Mc Kean-Cowdin R, Cotter SA, Tarczy-Hornoch K, Wen G, Kim JM, et al. (2013) Prevalence of amblyopia or strabismus in Asian and Non-
Hispanic White preschool children: Multi- ethnic pediatric eye disease study. Ophthalmology 120(10): 2117-2124

18. Pararajasegaram R (1999) Vision 2020-the right to sight: From strategies to action. Am J Ophthalmol 128(3): 357-358.

19. Kempen JH, Mitchell P, Lee KE, Tielsch JM (2004) The Prevalence of refractive errors among adults in the United States, Western Europe, and Australia. Arch Ophthalmol 122(4): 495-505.

20. Gwiazda J, Scheiman M, Mohindra I, Held R (1984) Astigmatism in children: Changes in axis and amount from birth to six years. Invest Ophthalmol Vis Sci 25(1): 88-92.

21. Taylor HR, (2000) Refractive errors: Magnitude of the need. Community Eye Health 13(33): 1-2.

22. Powell C, Wedner S, Hatt SR (2018) Vision screening for correctable visual acuity deficits in school-age children and adolescents. Cochrane Database of Systematic Reviews.

23. Saad A, Choudhury AH (2007) Prevalence of refractive error and low vision among school children in Cairo. East Mediterr Health J 13(3): 575-579.

24. Al Bahhawi T, Makeen AM, Daghreeri HH, Tobaigy MF, Adawi AM (2018) Refractive error among male primary school students in Jazan, Saudi Arabia: Prevalence and associated factors. The Open Ophthalmology Journal 12: 264-272.

25. Wedad M, Bardisi, Bakr M, bin Sadiq (2002) Vision screening of preschool children in Jeddah, Saudi Arabia. Saudi Med J; 23(4): 44-449.

26. Bener A, Al-Mahdi HS (2012) Internet use and television viewing in children and its association with vision loss: A major public health problem. J Public Health Africa 3(1): e16.

27. Pokharel A, Pokharel PK, Das H, Adhikari S (2010) The patterns of refractive errors among the school children of rural and urban settings in Nepal. Nepal J Ophthalmol 2(2): 114-120.

28. Singh H, Saini VK, Adav A, Soni B (2013) Refractive errors in school going children: data from a school screening survey programme. Natl J Community Med 4(1): 137-40.

29. Lin L, Chen CJ, Hung PT, Ko LS (1988) Nation-wide survey of myopia among schoolchildren in Taiwan, 1986. Acta Ophthalmol Suppl; 185: 29-33.

30. Khan AA, Nasti AR, Dar MA, Lone SA (2005) Prevalence of refractive errors in school children. JK Pract 12(3): 156-159.

31. Dirani M, Chan YJ, Gazzard G, Hornbeak DM, Leo SW et al. (2010) Prevalence of refractive error in Singaporean Chinese children: The strabismus, amblyopia, and refractive error in young Singaporean children (STARS) study. Investigative Ophthalmology \& Visual Science, 51(3): 1348-1355.

32. Giordano L, Friedman DS, Repka MX, Katz J, Ibironke J, et al. (2009) Prevalence of refractive error among preschool children in an urban population: The Baltimore pediatric eye disease study. Ophthalmology 116(11): 739-746.

33. Gronlund MA, Aring E, Hellstrom A, Landgren M, Stromland K (2004) Visual and ocular findings in children adopted from eastern Europe. Br J Ophthalmol 88(11): 1362-1367.

34. Tomkins O, Ben Zion I, Moore DB, Helveston EE (2011) Outcomes of pediatric cataract surgery at a tertiary care center in rural southern Ethiopia. Arch Ophthalmol 129(10): 1293-1297.

35. Lin H, Yang Y, Chen J, Zhong X, Liu Z, et al. (2014) Congenital cataract: Prevalence and surgery age at Zhongshan Ophthalmic Center (ZOC). PLoS One 9(7): e101781-e101781. 